\title{
Ultrasonographically detected gallbladder polyps: A reason for concern? A seven-year follow-up study
} Wolfgang Kratzer*†1, Mark M Haenle ${ }^{\dagger 1}$, Andrea Voegtle ${ }^{1}$, Richard A Mason², Atilla S Akinli ${ }^{1}$, Klaus Hirschbuehl ${ }^{3}$, Andreas Schuler ${ }^{4}$, Volker Kaechele ${ }^{1}$ and the Roemerstein study group

\begin{abstract}
Address: ${ }^{2}$ Zentrum für Innere Medizin, Klinik für Innere Medizin I, Universitätsklinikum Ulm, Robert-Koch-Str. 8, 89081 Ulm, Germany, ${ }^{2}$ University Hospitals of Cleveland Case Medical Center, Case Western Reserve, University School of Medicine 11100 Euclid Avenue, Cleveland Ohio 44106, USA, ${ }^{3}$ Zentralklinikum Augsburg, Abteilung Innere Medizin I, Stenglinstr. 2, 86156, Augsburg, Germany and ${ }^{4} H e l f e n s t e i n k l i n i k$ Geislingen, Medizinische Klinik, Eybstr. 16, 73312 Geislingen, Germany

Email: Wolfgang Kratzer* - wolfgang.kratzer@uniklinik-ulm.de; Mark M Haenle - mark.haenle@uniklinik-ulm.de; Andrea Voegtle - andrea.voegtle@oberschwabenklinik.de; Richard A Mason - richard.mason@uhhs.com; Atilla S Akinli - atilla.akinli@uniklinik-ulm.de; Klaus Hirschbuehl - klaus.kirschbuehl@klinikum-augsburg.de; Andreas Schuler - andreas.schuler@helfenstein-klinik.de; Volker Kaechele - volker.kaechele@uniklinik-ulm.de; the Roemerstein study group - wolfgang.kratzer@uniklinik-ulm.de

* Corresponding author †Equal contributors
\end{abstract}

Published: 15 September 2008

BMC Gastroenterology 2008, 8:4| doi:| 0.| | 86//47|-230X-8-4|
Received: 27 March 2008

Accepted: 15 September 2008

This article is available from: http://www.biomedcentral.com/I47I-230X/8/4 I

C 2008 Kratzer et al; licensee BioMed Central Ltd.

This is an Open Access article distributed under the terms of the Creative Commons Attribution License (http://creativecommons.org/licenses/by/2.0), which permits unrestricted use, distribution, and reproduction in any medium, provided the original work is properly cited.

\begin{abstract}
Background: The management of coincidental detected gallbladder polyps (GP) is still nebulous. There are few published data regarding their long-term growth. Objective of the present study was to investigate the prevalence and growth of gallbladder polyps in a survey of unselected subjects from the general population of a complete rural community.
\end{abstract}

Methods: A total of 2,4I5 subjects (I,26I women; I, I54 men) underwent ultrasound examination of the gallbladder, in November 1996 as part of a prospective study. Subjects in whom GP were detected at the initial survey underwent follow-up ultrasound examinations after 30 and 84 months.

Results: At the initial survey gallbladder polyps were detected in 34 subjects ( $1.4 \%$; females: $1.1 \%$, range 14 to 74 years; males: $1.7 \%$, range 19 to 63 years). Median diameter was $5 \pm 2.1 \mathrm{~mm}$ (range 2 to $10 \mathrm{~mm}$ ) at the initial survey, $5 \mathrm{~mm} \pm 2.8 \mathrm{~mm}$ (range 2 to $12 \mathrm{~mm}$ ) at 30 months and $4 \pm 2.3 \mathrm{~mm}$ (range 2 to $9 \mathrm{~mm}$ ) at 84 months. At the time of first follow-up no change in diameter was found in $81.0 \%(n=17)$, reduction in diameter in $4.8 \%(n=1)$ and increase in diameter in $14.3 \%(n=3)$. At the time of second follow-up no increase in polyp diameter was found in $76.9 \%(n=10)$ and reduction in diameter in $7.7 \%(n=I)$. No evidence of malignant disease of the gallbladder was found.

Conclusion: Over a period of seven years little change was measured in the diameter of gallbladder polyps. There was no evidence of malignant disease of the gallbladder in any subject. 


\section{Background}

The development and refinement of diagnostic imaging modalities such as computed tomography (CT), magnetic resonance imaging (MRI) and ultrasonography (US) and their widespread application have led to an increase in the coincidental diagnosis of gallbladder stones and gallbladder polyps $[1,2]$. As a result, clinicians are ever more frequently confronted with the question of how to proceed in cases of coincidentally discovered gallbladder polyps. The appropriate management of these entities remains controversial [3-5].

Gallbladder polyps represent a heterogeneous group of changes in the gallbladder wall and include entities such as cholesterol polyps, inflammatory polyps, adenomas, leiomyomas and lipomas [6]. The prevalence of gallbladder polyps is reported in the range of $0.3-9.5 \%$, depending on the population studied and on the study design. Prevalence figures in European studies fall in the range of $1.0-4.8 \%$, which is lower than reported in Southeast Asian populations [7-15]. In surgical and pathological studies, the prevalence of gallbladder polyps ranges from 0.004 to $13.8 \%$ [16].

To date, only a few studies have investigated the growth behavior of gallbladder polyps in follow-up [9,13,17-21]. Follow-up studies in cross sectional random samples have not been published. The majority of available data derive from surgical or ambulatory patients, or were conducted as part of preventive health measures (table 1) $[13,17,18,21]$.

Objective of the present study, conducted as part of a complete prospective sonographic survey of a rural population $[22,23]$, was to determine the prevalence of gallbladder polyps and their growth behavior in long-term follow-up.

\section{Methods}

In November and December 1996 we conducted a prospective epidemiological study on the prevalence of alveolar echinococcosis in Römerstein, a rural community in southwestern Germany. As part of this study, the population was also examined for gallbladder polyps $[22,23]$. Subjects were informed of the additional examination of the gallbladder at the time of the examination itself in order to minimize bias related to a potentially higher response rate on the part of inhabitants with upper abdominal complaints or disorders of the gallbladder. The present study was conducted in accordance with the principles of the Helsinki Declaration and was approved by the ethics commission of Ulm University.

\section{Ultrasound examinations}

All inhabitants aged six years and older were asked to present for examination after a four-hour fasting period. All study participants underwent ultrasound examination of the gallbladder at which gallbladder size in three axes, the gallbladder wall and gallbladder lumen were assessed. In cases of inconclusive findings regarding differentiation

Table I: Studies of the natural progression of gallblader polyps during follow up of patients and/or subjects

\begin{tabular}{|c|c|c|c|c|c|c|c|c|c|c|c|}
\hline \multirow[t]{2}{*}{$\begin{array}{l}\text { Author } \\
\text { Year }\end{array}$} & \multirow[t]{2}{*}{ Country } & \multirow[t]{2}{*}{ Population } & \multirow[t]{2}{*}{$\mathbf{n}$} & \multirow[t]{2}{*}{ Method } & \multirow[t]{2}{*}{$\begin{array}{l}\text { Follow-up } \\
\text { Period }\end{array}$} & \multicolumn{2}{|c|}{$\begin{array}{l}\text { Patients } \\
\text { undergoing } \\
\text { surgery }\end{array}$} & \multicolumn{4}{|c|}{$\begin{array}{l}\text { Changes in polyp diameter during the observation } \\
\text { period }\end{array}$} \\
\hline & & & & & & $N$ & & Reduction & Disappearance & Increase & Unchanged \\
\hline $\begin{array}{l}\text { Eelkema } \\
1962\end{array}$ & USA & Patients & 113 & $\begin{array}{l}\text { Cholecystogr } \\
\text { aphy }\end{array}$ & 15 years & & & & & & \\
\hline $\begin{array}{l}\text { Moriguchi } \\
1996\end{array}$ & Japan & Outpatients & 109 & Ultrasound & 5 years & 4 & No carcinoma & $1.9 \%$ & $1.9 \%$ & $11.7 \%$ & $84.5 \%$ \\
\hline $\begin{array}{l}\text { Shinkai } \\
\text { I } 988\end{array}$ & Japan & Patients & 60 & Ultrasound & $\begin{array}{l}\text { Average } 22 \\
\text { months }\end{array}$ & 9 & No carcinoma & $\begin{array}{l}\text { No } \\
\text { statistically } \\
\text { significant } \\
\text { change }\end{array}$ & $\begin{array}{l}\text { No statistically } \\
\text { significant } \\
\text { change }\end{array}$ & $\begin{array}{l}\text { No } \\
\text { statistically } \\
\text { significant } \\
\text { change }\end{array}$ & $\begin{array}{l}\text { No } \\
\text { statistically } \\
\text { significant } \\
\text { change }\end{array}$ \\
\hline $\begin{array}{l}\text { Heyder } \\
1990\end{array}$ & Germany & $\begin{array}{l}\text { Patients: } \\
\text { abdominal } \\
\text { screening in a } \\
\text { surgical } \\
\text { population }\end{array}$ & 92 & Ultrasound & $\begin{array}{l}\text { Average } 9 \\
\text { months }\end{array}$ & 2 & No carcinoma & No data & $13 \%$ & $6,5 \%$ & No data \\
\hline $\begin{array}{l}\text { Collett } \\
1998\end{array}$ & $\begin{array}{l}\text { New } \\
\text { Zealand }\end{array}$ & $\begin{array}{l}\text { Diabetics and } \\
\text { healthy controls }\end{array}$ & 564 & Ultrasound & $\begin{array}{l}2 \text { years }-30 \\
\text { patients } 5 \text { years - } \\
22 \text { patients }\end{array}$ & 0 & No surgery & No data & No data & No data & No data \\
\hline $\begin{array}{l}\text { Sugiyama } \\
2000\end{array}$ & Japan & Surgical patients & 125 & $\begin{array}{l}\text { Ultrasound/ } \\
\text { Endo- } \\
\text { ultrasound }\end{array}$ & $\begin{array}{l}\text { Average } 2.6 \\
\text { years }\end{array}$ & 3 & No carcinoma & $4 \%$ & $1.6 \%$ & $7.2 \%$ & $87.2 \%$ \\
\hline $\begin{array}{l}\text { Csendes } \\
2001\end{array}$ & Chile & $\begin{array}{l}\text { Surgical patients } \\
\text { with dyspeptic } \\
\text { symptoms or } \\
\text { routine } \\
\text { examination }\end{array}$ & 98 & Ultrasound & $\begin{array}{l}\text { Average } 5.9 \\
\text { years Range } \\
24-144 \text { months }\end{array}$ & 14 & No carcinoma & $2 \% 1 / 27 \%$ & $18 \% 1 / 210 \%$ & $5 \%^{3}$ & $53 \% 1 / 272 \%$ \\
\hline
\end{tabular}

I after 8 years; ${ }^{2}$ after 12 years; ${ }^{3}$ after 4 years 
between gallbladder stones and gallbladder polyps, patients were examined in standing position.

The initial ultrasound examinations in 1996 were carried out by 8 assistants of the University Hospital of Ulm in 4 cubicles, where examinations were performed simultaneously. All personnel had been trained by the same experienced ultrasound examiner before the study, and this examiner was present in the examination room to provide a second opinion in cases in which the primary examiner could not give a definite diagnosis. The ultrasound examinations in 1999 and 2003 were all performed by the same experienced examiner.

The diagnosis of gallbladder polyps was made on the basis of the following criteria: hyperechoic structures without acoustic shadow that projected from the gallbladder wall into the gallbladder lumen and were either pedunculate or broad based; unequivocal visualization in two planes (longitudinal and in cross-section); no change in position of the wall change secondary to change in subjects' position; unremarkable gallbladder wall; unequivocal differentiation between a gallbladder septum and a gallbladder polyp. The diagnosis of "gallbladder polyp" was made only in cases fulfilling all the above criteria.

Ultrasound examinations were performed using three different types of ultrasound scanners (two units of the type ATL 800 and one ATL 9 HDI, manufactured by ATL Ultrasound Medical Systems, Bothell, WA, USA, each with either a 3.5-5 MHz or 4-7 MHz convex transducer head; and a Siemens Sonoline 400, manufactured by Siemens AG, Erlangen, Germany with a $5 \mathrm{MHz}$ convex transducer head) by trained examiners working under supervision. The number of polyps and the diameter in millimeters of the largest polyp were then documented.

\section{Follow-up 1999}

Subjects diagnosed with gallbladder polyps at the initial survey in 1996 were sent a written invitation in May 1999 for follow-up examination. Follow-up examinations were conducted 30 months after the initial survey from May $25^{\text {th }}$ to June $5^{\text {th }} 1999$. Of 34 subjects diagnosed with gallbladder polyps, $31(91 \%)$ accepted the invitation. Two subjects did not respond to the written invitation, while the third refused the follow-up examination for personal reasons.

The ultrasound examinations were conducted using a Philips ATL HDI 5000 scanner with a 2-5 MHz convex transducer head. An increase or decrease in the diameter of the polyp was defined as a size change of greater than 2 $\mathrm{mm}$.

\section{Follow-up 2003}

The second follow-up examination took place in October and November 2003 at 84 months after the initial survey. With the help of the Civil Registry Office of Römerstein, all 31 subjects participating in the first follow-up examination in 1999 were located. It was discovered that four individuals had moved, while one participant had died. The remaining 26 participants were sent a written invitation and were also contacted by telephone. Subjects were given the choice of being examined either at the University Hospital of Ulm or in Römerstein (school center). In order to maximize the response rate, subjects were also offered the option of being examined at home using a portable ultrasound scanner. Three subjects came to Ulm, while 14 were examined in Römerstein (school center) and five were examined in their homes. Examinations in Ulm and Römerstein were again conducted using a Philips ATL HDI 5000 scanner with a 2-5 MHz and 4-7 $\mathrm{MHz}$ convex transducer heads. Subjects examined in their homes were scanned using a portable SONOACE My Sono 201 scanner with a $2-5 \mathrm{MHz}$ convex transducer head.

Three of the 26 subjects had undergone cholecystectomy in the intervening period. One further subject refused to participate in the follow-up examination for personal reasons. Thus, of the remaining 26 subjects, $22(64.7 \%, \mathrm{n}=$ 34; 14 males, eight females) participated in the second follow-up examination. Nine subjects could not be examined at follow-up: four had moved, one had died and three had undergone cholecystectomy.

\section{Statistics}

Because of the small number of subjects, data were analyzed descriptively.

\section{Results}

Of the total 3,841 registered inhabitants of the community of Römerstein six years of age or older, $66.6 \%(\mathrm{n}=$ 2,560 ) participated in the initial survey in 1996. Excluded from the study were 145 initial respondents $(5.7 \%)$, of whom $82(3.2 \%)$ had undergone prior cholecystectomy. Sixty-two subjects $(2.4 \%)$ were excluded because of inability to adequately visualize the gallbladder, while one subject $(0.04 \%)$ was found to have both a gallbladder stone and a gallbladder polyp. At the initial examinations in 1996, gallbladder findings suggestive of malignancy were not identified in any subject.

\section{Prevalence}

The study population consisted of $\mathrm{n}=2,415$ subjects (1,261 women, median age 41.5 years, range $14-74$ years; 1,154 men, median age 39 years, range 19-63 years). Sonographic criteria for gallbladder polyps were documented in $1.4 \%$ of subjects $(\mathrm{n}=34 ; 1.1 \%$ in females; 
$1.7 \%$ in males). The highest prevalence of gallbladder polyps was observed in the group of subjects 36-45 years of age (females, 2.1\%; males, $4.7 \%$; figure 1 ). In the same study population, the prevalence of gallbladder stones was $7.8 \%$ (10.5\% in females, $4.9 \%$ in males; 23 ).

\section{Number and diameter of polyps}

Data on polyp size are limited to $n=31$ subjects because documentation of the diameter of polyps was not available in three subjects. The diameter of the largest polyp was $5 \mathrm{~mm}$ or less in 20 of 31 subjects $(64.5 \%)$ and between 6 $\mathrm{mm}$ and $10 \mathrm{~mm}$ in 11 of 31 subjects (35.5\%). No polyps were larger than $10 \mathrm{~mm}$. Median polyp diameter was 5 $\mathrm{mm} \pm 2.1 \mathrm{~mm}$ (range $2-10 \mathrm{~mm}$ ) for all subjects; $4 \mathrm{~mm} \pm$ $2.2 \mathrm{~mm}$ (range $2-9 \mathrm{~mm}$ ) in females; and $5 \mathrm{~mm} \pm 2.1 \mathrm{~mm}$ (range $4-10 \mathrm{~mm}$ ) in males. Of the total 34 subjects with identified polyps, $85.3 \%$ had solitary polyps, while $14.7 \%$ had multiple polyps ( 2 polyps in two subjects, 3 polyps in two subjects, more than 5 polyps in one subject). All polyps were pedunculate. Broad-based polyps were not observed in any subject

\section{Follow-up 1999}

Of 34 subjects with identified gallbladder polyps at the time of the initial survey, 31 (91.2\%; 13 women, 18 men) presented to the first follow-up examination. At the time of the first follow-up examination, polyps were again identified in 24 subjects $(77.4 \%, \mathrm{n}=31)$. Polyps were no longer visualized in seven subjects. Among these seven subjects, two female subjects, however, had newly diagnosed gallbladder stones (figure 2). Median polyp diame- ter was $5 \mathrm{~mm} \pm 2.8$ (range $2-12 \mathrm{~mm}$ ). Polyp diameter was less than $10 \mathrm{~mm}$ in $91.7 \%(22 / 24)$ of cases and less than $5 \mathrm{~mm}$ in $45.8 \%(11 / 24)$ of cases. Two polyps (2/24; $8.3 \%$ ) were larger than $12 \mathrm{~mm}$. In $81.0 \%$ (17/21) of cases, polyp size remained constant, while, in one subject $(1 / 21$; $4.8 \%$ ), polyp diameter decreased and in three subjects (3/ $21,14.3 \%$ ), growth progression was observed (figure 2). In one subject, polyp diameter had doubled from 4 to 8 $\mathrm{mm}$. Unfortunately, this subject left the community shortly after the first follow-up examination, preventing further follow-up. Examination of the two other subjects revealed size increase from 9 to $12 \mathrm{~mm}$. Because of polyp size greater than $10 \mathrm{~mm}$, these patients had been advised to consider cholecystectomy and subsequently did undergo the procedure. Histopathological studies in one subject revealed multiple gallbladder stones in an otherwise unremarkable gallbladder, while, in the second, cholecystitis of moderate severity was diagnosed. These three subjects with increases in polyp diameter did not report upper abdominal complains, nausea or vomiting, or intolerance of fatty foods; two, however, reported infrequent heartburn.

\section{Follow-up 2003}

In the remaining 22 subjects, polyps were no longer visualized in nine persons. In three of these subjects, the first follow-up examination in 1999 had also failed to visualize polyps; follow-up in 2003 showed that no new sonographically visualized polyps had developed in the fouryear interval in these subjects. Among the remaining four subjects without polyps, two were found to have devel-

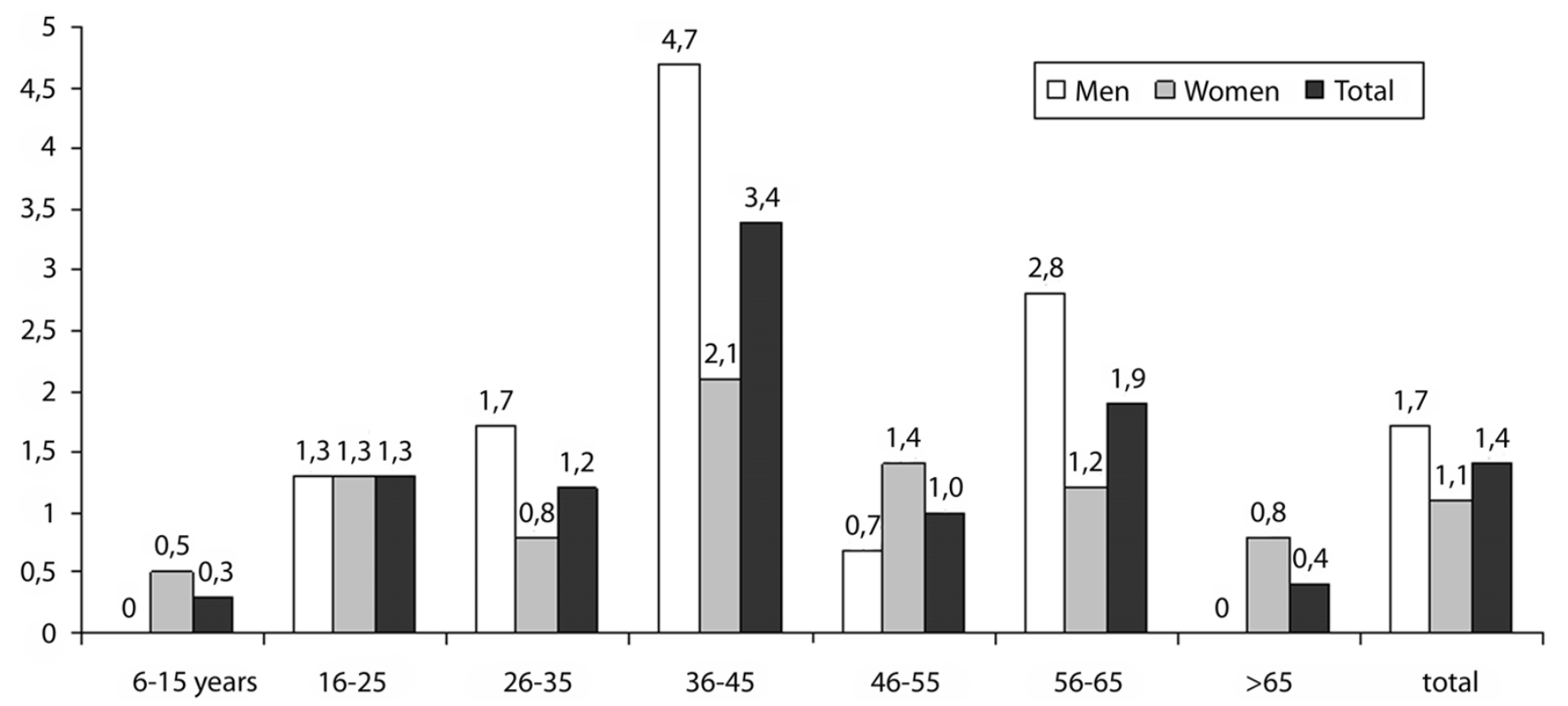

Figure I

Gallbladder polyps: prevalence in percent (\%) in relation to age and sex at the initial survey in 1996. 


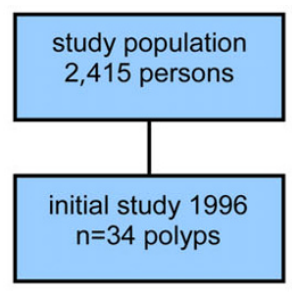

lost-to-follow-up $n=3^{*}$
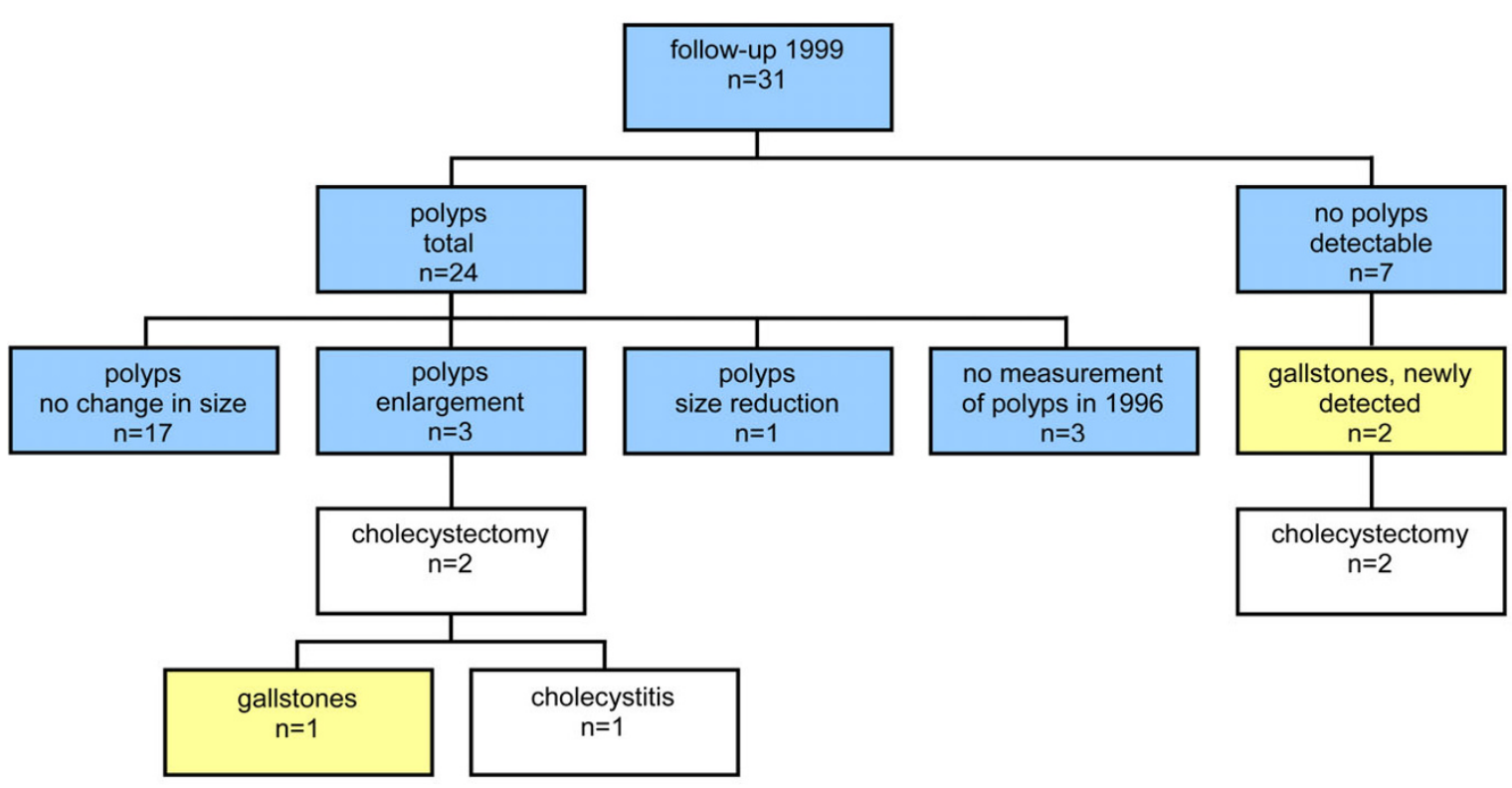

Lost-to-follow-up $n=9^{\dagger}$

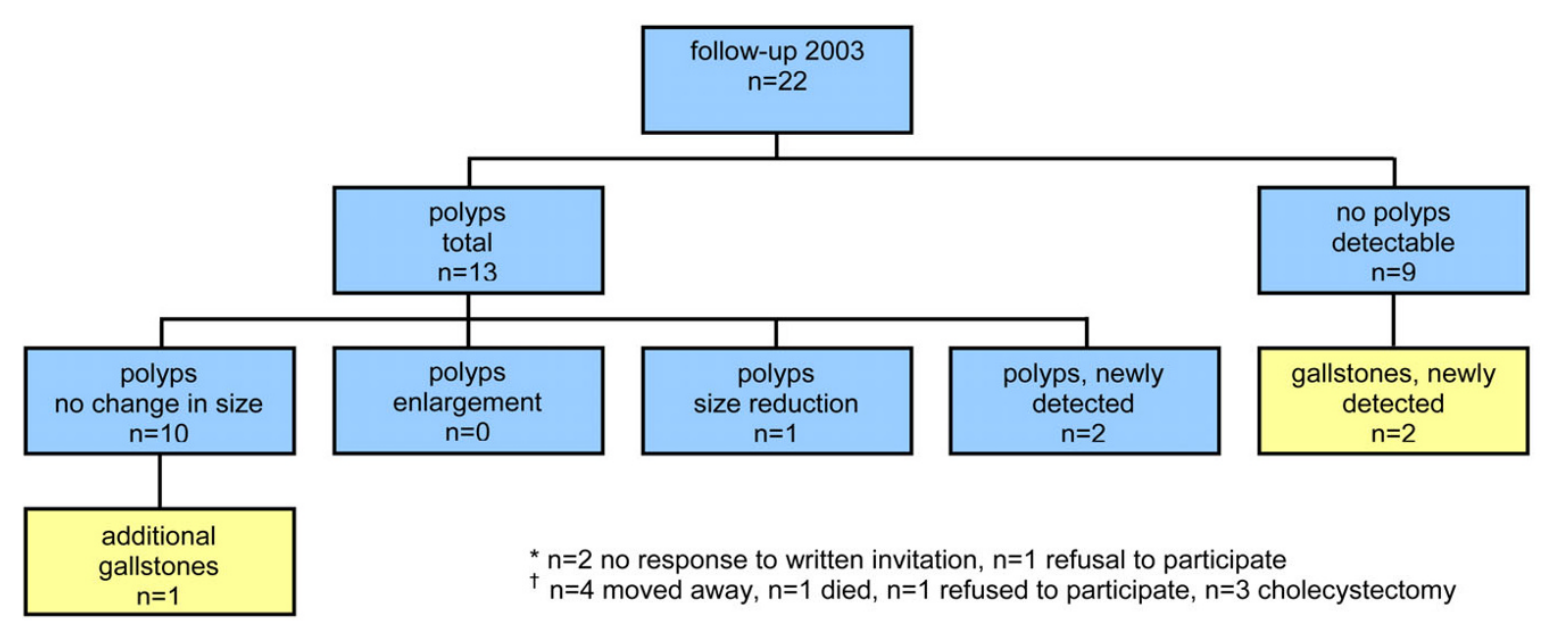

Figure 2

Initial study population in 1996 and results and ultrasound findings in 1999 and 2003. 
oped gallbladder stones in the interval. In one other female subject, the findings of cholecystolithiasis from the first follow-up examination in 1999 was confirmed (figure 2).

Polyp diameter remained constant in $76.9 \%$ (10/13) subjects. In one subject $(1 / 13 ; 7.7 \%)$ a polyp decreased in size. Two subjects $(2 / 13 ; 15.4 \%)$, in whom the first follow-up examination in 1999 had failed to visualize the polyps found at the initial survey in 1996, again met sonographic criteria for the diagnosis of gallbladder polyps. A comparison of median polyp size over seven years suggests that their diameter does not significantly change. In all examinations, females had a smaller polyp diameter than did males. Thickening of the gallbladder wall was not observed in any subject. Median diameter of polyps for all subjects was $4 \mathrm{~mm} \pm 2.3$ (range $2-9 \mathrm{~mm}$ ), for women, $4 \mathrm{~mm}$ and for males, $5 \mathrm{~mm}$. For the whole population, $53.8 \%(7 / 13)$ of polyps were smaller than $5 \mathrm{~mm}$, while 46.2\% (6/13) showed a diameter between 6 and 9 $\mathrm{mm}$.

\section{Discussion}

\section{Prevalence study}

The prevalence of gallbladder polyps in our population sample was $1.4 \%$ (males, $1.7 \%$; females $1.1 \%$ ), which corresponds to prevalence data published by Özmen et al. for Great Britain and by Heyder et al, for Germany $[7,9]$. Our data were collected as part of a complete survey of a rural population with a response rate of $66.6 \%[22,23]$. To date, the only available data regarding the prevalence of gallbladder polyps in a representative population sample were published by Jørgensen et al., who reported a prevalence of $4.6 \%$ for males and $4.3 \%$ for females [8]. Prevalence data from larger, non-surgical patient populations derive from preventive medical studies or from selected populations in Japan and Taiwan, with prevalences in the range of 5.3-9.5\% [10-14]. All studies show a predominance of males for the development of gallbladder polyps, compared to a female predominance for the development of gallbladder stones [10-14,23,24]. In our study, the peak age for first manifestation of gallbladder polyps lay between 36 and 45 years. In this age group, the respective prevalences for males and females stood at $4.7 \%$ and $2.1 \%$, respectively. Segawa and Lin reported the highest prevalence for both sexes in the fourth decade of life $[10,15]$. Similarly, Okamoto and Jørgensen found the highest prevalence in males in the fourth decade, but in the fifth and sixth decades in females $[8,10,11,15]$.

\section{Follow-up study}

To date, no data on the follow-up of gallbladder polyps derived from studies of representative population samples have been published. Of published studies, the majority used diagnostic ultrasound, while Eelkema et al. analyzed data obtained by cholecystography and Sugiyama et al. examined some of their patients using endosonography. Most subjects were surgical patients, although Collett et al. report on diabetics and healthy controls $[9,13,14,17$ 21]. The average follow-up periods of the available studies range from nine months to 15 years. In most instances, patients were re-examined at intervals of six or 12 months. Similar to the study by Collett et al., we examined our subjects at established follow-up dates of three and seven years [19].

All gallbladder polyps diagnosed at the initial survey were $10 \mathrm{~mm}$ or less in diameter. A similar distribution was reported by Moriguchi et al., who reported diameters 5 $\mathrm{mm}$ and less in 57\%, 6-9 $\mathrm{mm}$ in $37 \%$ and $10 \mathrm{~cm}$ and above in only $6 \%$ [13]. Jørgensen et al. and Csendes et al. reported diameters $<5 \mathrm{~mm}$ in even higher percentages of subjects, namely $85 \%$ and $80 \%$, respectively, and did not, in their respective populations, identify any polyps larger than $10 \mathrm{~mm}$ in diameter $[8,17]$. The median polyp diameter in our initial survey was $5 \mathrm{~mm} \pm 2.1 \mathrm{~mm}$ (range 2-10 $\mathrm{mm}$ ), which was comparable to data reported by Shinkai et al. at $4.8 \mathrm{~mm} \pm 2.9 \mathrm{~mm}$. In the study reported by Collett et al., the average initial diameter was $3.9 \mathrm{~mm}$. Heyder et al., however, reported larger diameters at $6 \mathrm{~mm}$ (range 2-15 mm) $[9,19,20]$.

With respect to diameter, the majority of polyps showed no change at either the first (1999) or second (2003) follow-up examination. In 1999, polyp diameter remained constant in $81 \%(17 / 21)$ of subjects, with one person $(5 \%)$ exhibiting reduction in the size of his polyp and three persons (14\%) showing size progression (figure 3). A comparison of size progression between 1999 and 2003 shows that $91 \%(10 / 11)$ of polyps remained constant, one became smaller $(1 / 11 ; 9 \%)$ but none became larger. Over the entire 84 -month period $62 \%(8 / 13)$ of polyps showed no change in size, $15 \%(2 / 13)$ became smaller and 23\% (3/13) became larger. Thus, our results lie between data published by Moriguchi and Sugiyama on the one hand and those of Csendes on the other $[13,17,18]$. Over an observation period of five years, Moriguchi et al. found an increase in polyp diameter in $11.7 \%(12 / 103)$, while in $84.5 \%$ (87/103), polyp size remained constant. Conversely, Csendes et al., who followed subjects for an average $71 \%$, found no change in polyp diameter in $50 \%$ of subjects while an increase or decrease in diameter was observed in $25 \%$ each (table 1 ) $[13,17]$.

At the first follow-up examination, 30 months after the initial survey and with a response rate of $91 \%$, polyps were visualized in only $77 \%$ (24/31) of subjects; at the second follow-up examination, 84 months after the initial survey and with a response rate of $65 \%$, polyps were iden- 


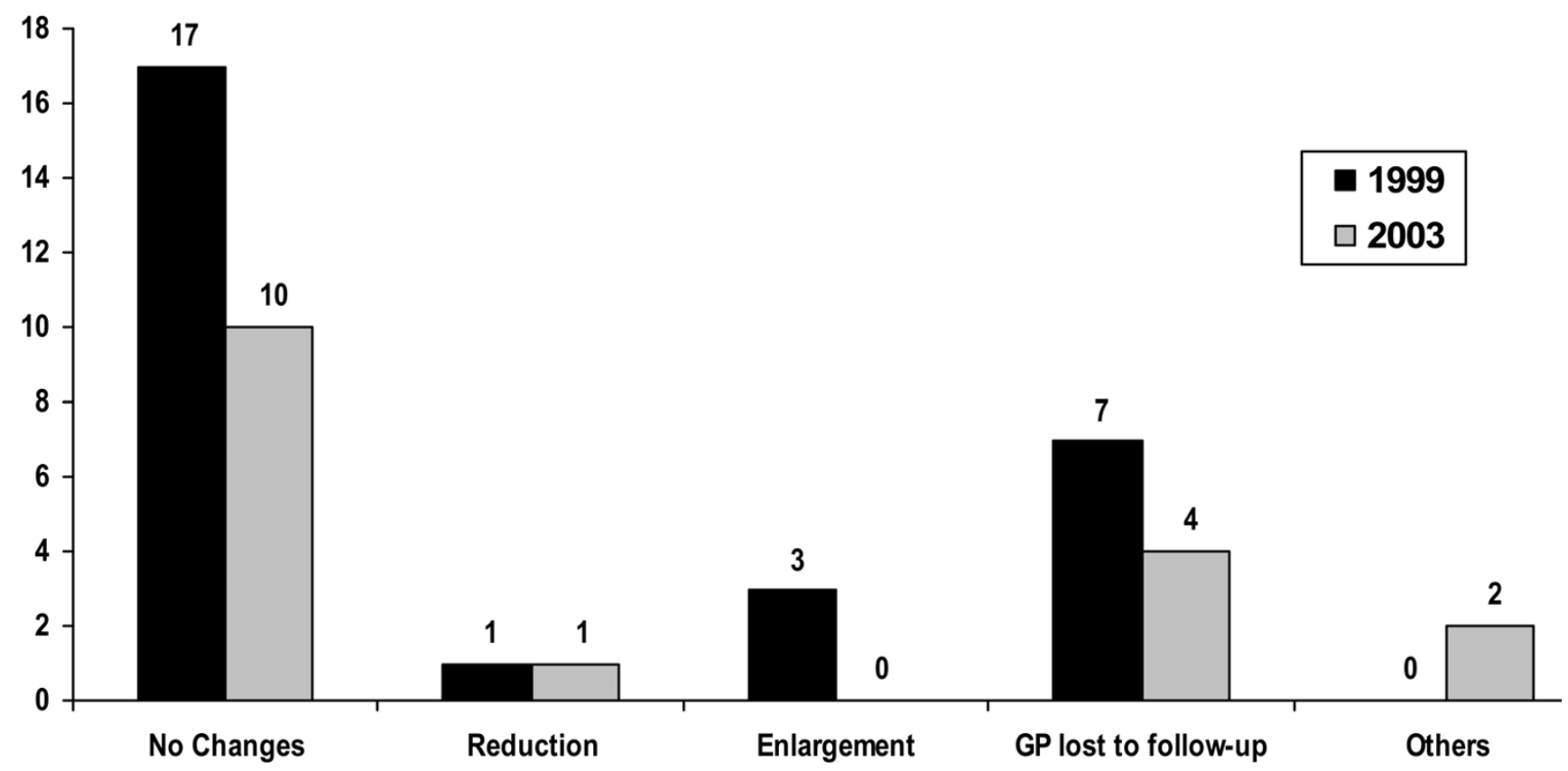

Figure 3

Changes in gallbladder polyps (GP) between 1996 and 1999 and between 1996 and 2003.

tified in $41.9 \%(13 / 31)$ of subjects. The proportion of polyps that were no longer detected at follow-up examinations was lower in reports by other authors [13,17-19].

Of the three subjects in our study who exhibited polyps with size progression, two underwent cholecystectomy. The histopathological findings in one patient revealed multiple gallbladder stones in an otherwise unremarkable gallbladder. In all, $19.4 \%(n=6)$ of all structures initially identified as polyps were identified as gallbladder stones at follow-up. Similar results have been reported from surgical series $[6,4,25,26]$.

A possible reason for the false-positive ultrasound findings might be that polyps may form the site of origin in the development of gallbladder stones [6,27].

The histopathological findings in the second subject who had undergone cholecystectomy due to size progression revealed cholecystitis of moderate severity, which, at the time of the ultrasound examination, may have been polypoid in appearance $[27,28]$. A further reason for the failure to demonstrate polyps at histopathological examination could be that polyps may be destroyed by the mechanical action of the gallbladder wall.[8] This may also be an explanation for the observation in our study that the prevalence of gallbladder polyps among women and in advanced age is lower, while, at the same time, in this subsample, the prevalence of gallbladder stones is higher to a statistically significant extent. [23] Neither Sugiyama nor Moriguchi nor Csendes reported the development of gallbladder stones at follow-up $[17,18,20]$.

One of the limitations of our study is the small number of only 34 subjects with polyps visualized at ultrasound. One reason may relate to the technically less advanced ultrasound scanners used at the initial survey compared with those used at follow-up. The portable ultrasound scanner used at the second follow-up examination of subjects in their homes may also have limited the strength of the findings and may possible have been the cause of false-negative findings.

\section{Conclusion}

The present study for the first time examined the growth behavior of gallbladder polyps in a representative population sample. In summary, we can conclude that the changes in size in the polyps over an observation period of seven years were slight. Size progression was observed in only three subjects. No evidence of development of malignant disease was observed. Remarkable was the high number of gallbladder stones at follow-up, which initially were diagnosed as gallbladder polyps.

\section{Competing interests}

The authors declare that they have no competing interests. 


\section{Authors' contributions}

WK conceived and designed the study, acquired, analysed and interpreted data, and drafted the manuscript. $\mathrm{MMH}$ collected, assembled and interpreted the data and drafted the manuscript. AV collected, assembled and interpreted the data and revised the manuscript for important intellectual content. RAM drafted the manuscript. AA analysed and interpreted the data, and revised the manuscript for important intellectual content. KH acquired, analysed and interpreted data, and revised the manuscript for important intellectual content. AS revised the manuscript for important intellectual content. VK helped conceive and design the study, acquired, analysed and interpreted data, and drafted the manuscript. All authors approved the final version of the manuscript. WK is guarantor.

\section{Acknowledgements}

Members of the Roemerstein study group (in alphabetical order): Karlheinz Beckh, Birgit Bilger, Anke Dinkel, Willy A. Flegel, Matthias Frosch, Wilhelm Gaus, Bruno Gottstein, Birgit Hay, Lars Jenne, Peter Kern, Petra Kern, Jochen Kilwinski, Peter Kimmig, Klaus Koerner, Wolfgang Kratzer, Martina Kron, Richard Lucius, Peter Merkle, Michael Merli, Karin Naser, Martina Orth, Thomas Romig, Hanns Martin Seitz, Hans Sigel, Franz F. Wagner.

This publication is dedicated to our colleague, Carmen Frey, who died in a tragic car accident. She played an important role in the planning and carrying out of the follow-up examinations and in the analysis of the initial prevalence data. She is very much missed, both as a colleague to whom we could always turn, and as a devoted friend.

\section{References}

I. Blonski W, Reddy KR: Evaluation of nonmalignant liver masses. Curr Gastroenterol Rep 2006, I:38-45.

2. Choi BY, Nguyen MH: The diagnosis and management of benign hepatic tumors. J Clin Gastroenterol 2005, 39:40 I-4I2

3. Myers RP, Shaffer EA, Beck PL: Gallbladder polyps: Epidemiology, natural history and management. Can J Gastroenterol 2002, 16:187-194.

4. Boulton R, Adams D: Gallbladder polyps: when to wait and when to act. Lancet 1997, 349:817-818.

5. Johnson CD: Polypoid lesions of the gall bladder. Gut 1997, 4I:577-578.

6. Christensen $\mathrm{AH}$, Ishak KG: Benign tumors an pseudotumors of the gallbladder. Report of $\mathbf{1 8 0}$ cases. Arch Pathol 1970, 90:423-432.

7. Ozmen MM, Patankar RV, Hengirmen S, Terzi MC: Epidemiology of gallbladder polyps. Scand J Gastroenterol 1994, 29:480.

8. Jørgensen T, Jensen KH: Polyps in the gallbladder. A prevalence study. Scand J Gastroenterol 1990, 25:28I-286.

9. Heyder N, Günter E, Giedl J, Obenauf A, Hahn EG: Polypoid lesions of the gallbladder. Dtsch Med Wochenschr 1990, I I 5:243-247.

10. Lin WR, Lin DY, Tai DI, Hsieh SY, Lin CY, Sheen IS, Chiu CT: Prevalence of and risk factors for gallbladder polyps detected by ultrasonography among healthy Chinese: Analysis of 34669 cases. J Gastroenterol Hepatol 2008, 23(6):965-9.

II. Okamoto M, Okamoto H, Kitahara F, Kobayashi K, Karikome K, Miura K, Matsumoto Y, Fujino MA: Ultrasonographic Evidence of Association of Polyps and Stones With Gallbladder Cancer. Am J Gastroenterol 1999, 94:446-450.

12. Chen CY, Lu CL, ChFLee SD: Risk factorsfor gallbladder polyps in the Chinese population. Am J Gastroenterol 1997, 92:2066-2068.

13. Moriguchi H, Tazawa J, Hayashi Y, Takenawa H, Nakayama E, Marumo F, Sato C: Natural history of polypoid lesions in the gall bladder. Gut 1996, 39:860-862
14. Shinchi K, Kono S, Honjo S, Imanishi K, Hirohata T: Epidemiology of gallbladder polyps: an ultrasonographic study of male selfdefense officials in Japan. Scand J Gastroenterol 1994, 29:7-I0.

15. Segawa K, Arisawa T, Niwa Y, Suzuki T, Tsukamoto Y, Goto H, Hamajima E, Shimodaira M, Ohmiya N: Prevalence of gallbladder polyps among apparently healthy Japanese: ultrasonographic study. Am J Gastroenterol 1992, 87:630-633.

16. Mainprize KS, Gould SWT, Gilbert JM: Surgical management of polypoid lesions of the gallbladder. Br J Surg 2000, 87:4I4-4I7.

17. Csendes A, Burgos AM, Csendes P, Smok G, Rojas J: Late FollowUp of Polypoid Lesions of the Gallbladder Smaller Than 10 mm. Ann Surg 200I, 234:657-660.

18. Sugiyama M, Atomi $Y$, Yamato T: Endoscopic ultrasonography for differential diagnosis of polypoid bladder lesions: analysis in surgical and follow up series. Gut 2000, 46:250-254.

19. Collett JA, Allan RB, Chisholm RJ, Wilson IR, Burt MJ, Chapman BA: Gallbladder Polyps: Prospective Study. J Ultrasound Med 1998, I 7:207-2 II.

20. Shinkai H, Kimura W, Muto T: Surgical Indications for Small Polypoid Lesions of the Gallbladder. Am J Surg 1998, 175:1|4-II7.

21. Eelkema HH, Hodgson JR, Stauffer MH: Fifteen-year follow-up of polypoid lesions of the gall bladder diagnosed by cholecystography. Gastroenterology 1962, 42: 144-I47.

22. Romig T, Kratzer W, Kimmig P, Frosch M, Gaus W, Flegel WA, Gottstein B, Lucius R, Beckh K, Kern P: An epidemiologic survey of human alveolar echinococcosis in southwestern Germany. Romerstein Study Group. Am J Trop Med Hyg 1999, 61:566-573.

23. Kratzer W, Kron M, Hay B, Pfeiffer MM, Kächele V: Prevalence of cholecystolithiasis in South Germany - an ultrasound study of 2,498 persons of a rural population. Z Gastroenterol 1999 , 37:1 I57-1 162.

24. Kratzer W, Mason RA, Kachele V: Prevalence of gallstones in sonographic surveys worldwide. J Clin Ultrasound 1999, 27: I-7.

25. Damore LJ 2nd, Cook CH, Fernandez KL, Cunningham J, Ellison EC, Melvin WS: Ultrasonography incorrectly diagnoses gallbladder polyps. Surg Laparosc Endosc Percutan Tech 200I, I I:88-9I.

26. Chattopadhyay D, Lochan R, Balupuri S, Gopinath BR, Wynne KS: Outcome of gall bladder polypoidal lesions detected by transabdominal ultrasound scanning: a nine year experience. World J Gastroenterol 2005, I I:2171-2173.

27. Levy AD, Murakata LA, Abbott RM, Rohrmann CA: From the archives of the AFIP. Benign tumors and tumorlike lesions of the gallbladder and extrahepatic bile ducts: radiologic-pathologic correlation. Armed Forces Institute of Pathology. Radiographics 2002, 22:387-4I3.

28. Vriesman AC van Breda, Engelbrecht MR, Smithuis RH, Puylaert JB: Diffuse gallbladder wall thickening: differential diagnosis. AJR Am J Roentgenol 2007, 188:495-50।.

\section{Pre-publication history}

The pre-publication history for this paper can be accessed here:

\section{http://www.biomedcentral.com/1471-230X/8/41/pre} pub

Publish with Biomed Central and every scientist can read your work free of charge

"BioMed Central will be the most significant development for disseminating the results of biomedical research in our lifetime. "

Sir Paul Nurse, Cancer Research UK

Your research papers will be:

- available free of charge to the entire biomedical community

- peer reviewed and published immediately upon acceptance

- cited in PubMed and archived on PubMed Central

- yours - you keep the copyright 